\title{
INFLUENCE OF THE INTERNAL CLEARANCE OF BALL BEARINGS ON THE VIBRATION LEVEL
}

\author{
P. Zmarzly*
}

\begin{abstract}
The paper presents research of the influence of the radial internal clearance of the rolling ball bearings on the basic exploitation parameter which is the level of vibration. The measuring method of radial internal clearance of rolling bearings and measuring device are described. The 6304 type ball rolling bearings were used in research. The experimental research consisted of measurements of radial internal clearance and vibration level. The vibration analysis was divided into three basic frequency bands: low (50$300 \mathrm{~Hz})$, medium (300-1800 Hz) and high (1800-10 $000 \mathrm{~Hz})$. The research was carried out in Laboratory of Rolling-Elements Bearings located in Kielce University of Technology. The research results showed that the increase of the radial clearance values affect the level of vibration generated by rolling bearings. The biggest influence was noted in the medium vibration frequency band.
\end{abstract}

Keywords: rolling element bearing, internal clearance, vibration, Anderon unit

\section{Introduction}

The rolling element bearings are one of the most important components of rotating machinery. The main functions of rolling bearing are reducing of rolling resistance and carries radial and axial loads. A ball bearing uses balls to maintain the separation between the bearing races. This type of the bearing plays a crucial role in industrial application for example in automotive, aerospace and household appliances. Rolling bearing life depends on many features that can be divided into design features, exploitation features and technological features. One of the most important design feature of bearing is radial and axial internal clearance. The internal clearance affects the friction between rolling elements and races. Furthermore, the load zone in the bearing is associated with the value of the internal clearance. Another important parameter is operating temperature of rolling bearing. The temperature of the inner race and rotating elements is usually higher than the outer race. The temperature difference between the inner and outer races reduces the bearing radial clearance. Therefore, the analysis of heat transfer in rolling bearing should be conduct (Błasiak, 2016). Appropriately value of bearing clearance affects the proper operation of the machine or device where rolling bearing is mounted (Smolík et al., 2017). In many cases, despite that bearings balls and races were manufactured in accordance with the assumed requirements, excessive value of internal clearance may cause increase vibration generated by rolling bearing. This is an unfavourable phenomenon. Vibration analysis is a powerful tool to assess condition of rolling element bearings (Adamczak et al., 2017b and Kıral, 2006). Rolling bearings manufacturers strive to produce their products characterized by low vibration emission. Excessive vibration value may indicate micro damages of rolling elements and raceways (Cui et al., 2016), lubrication contamination or bearings construction defects (Petersen et al., 2015). Manufacturers usually do not present detailed values of internal clearance of rolling bearings. Therefore, there is a need to carry out research aimed at measuring real values of radial clearance of the bearing groups and relate the obtained values to the bearings vibration level. This will allow to determine how the values of radial clearance affects vibration level generated by rolling bearing. In addition, there is a limited number of research works related to examination of internal clearance of rolling bearing.

Eng. Paweł Zmarzły, PhD: Chair of Mechanical Technology and Metrology, Kielce University of Technology, Al. 1000-lecia P. P. 7, 25-314 Kielce; PL, pzmarzly@tu.kielce.pl 


\section{Bearing internal clearance}

Bearing internal clearance is defining as the total distance through which one bearing ring is moved relative to the other ring. Radial displacement is defining as radial clearance $-\Delta \mathrm{R}$ (see Fig. 1a), whereas axial displacement is defined as axial clearance $-\Delta \mathrm{L}$ (see Fig. 1b). Figure 1 shows the radial and axial internal clearance of ball bearing.
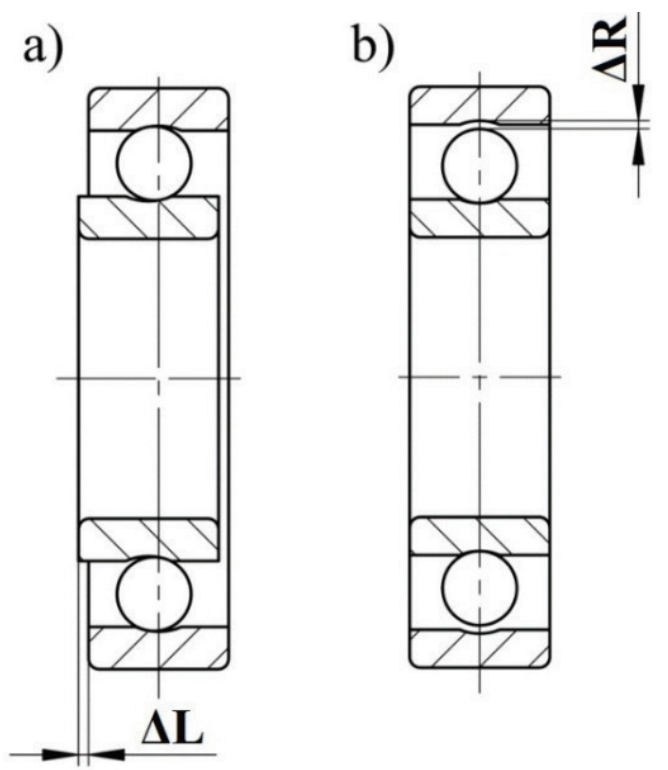

Fig. 1: Bearing internal clearance: a) axial clearance ( $\Delta L)$, b) radial clearance $(\Delta R)$.

Accordingly to the standard ISO 5753 there are five groups of radial internal clearance. The rolling bearings with larger radial clearance should be slightly loaded and can be used at a high speed. The increase of the radial clearance reduces the frictional resistance which is undoubted advantage. However, its excessive value reduces load bearing capacity and service life of the rolling bearings. In practice, the bearing with enlarged radial clearance are used more often. Hence, bearing with reduced radial and axial clearance are mainly used depending on the design requirements of the machine where they are used.

\subsection{Radial clearance measurement}

The radial clearance of rolling bearing can be directly measured using measuring device or can by calculated using geometrical relationships (Aschenbrenner, 2017 and Kaczor, 2014). In the research presented in this paper, the radial clearance was measured using measuring devices developed at the Kielce University of Technology. The Figure 2 shows the photography of radial clearance measuring device and it measuring principle.

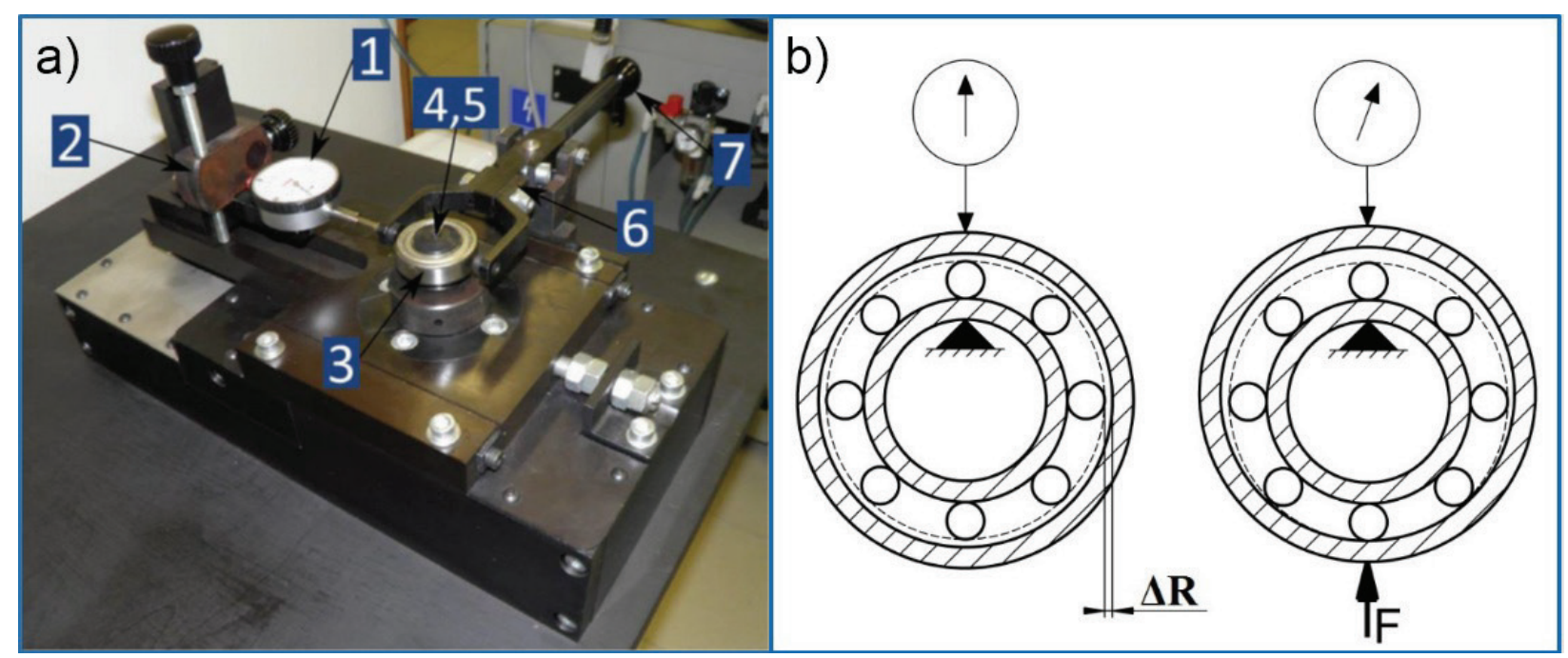

Fig. 2: Radial clearance measurement: a) measuring device, b) principle of measurement. 
The main element of measuring device is dial gauge (1) mounted in the holder (2). Examined bearing (3) is slid onto the shaft (4). Holdfast (5) prevents from changing the position of the examined bearing. The radial load $\Delta \mathrm{F}$ is applied to the bearing outer ring by the holder (6) moved by lever (7). Displacement of the outer ring relative to the inner ring determines the value of the radial clearance that is read from the dial gauge (1). The value of the radial load is chosen in order not to deform the elements of the bearing.

\section{Experimental study}

Fifty ball bearings types 6304 were used in research. The natural frequencies of investigated bearings were as follows: frequency from rotation: $30 \mathrm{~Hz}$, frequency from outer ring: $77 ., 22 \mathrm{~Hz}$, frequency from inner ring: $132.78 \mathrm{~Hz}$, frequency from balls: $105.45 \mathrm{~Hz}$. The first step of research procedure was measurement of vibration velocity using measuring device known as Anderometer (Adamczak, 2017a). The examined bearings were mounted on spindle. Next the pneumatic clamp ensures a constant axial load equals $65 \mathrm{~N}$. The motor of measuring device rotates the spindle at $1800 \mathrm{~min}^{-1}$ in accordance with the recommendations presented in the ISO 15242-1:2004 standard. A piezoelectric sensor measure vibration velocity of examined bearings. The vibration analysis was carried out in three vibration frequency bands: low LB $(50-300 \mathrm{~Hz})$, medium MB $(300-1800 \mathrm{~Hz})$ and high HB $(1800-10000 \mathrm{~Hz})$. The vibration level was expressed in the Anderon unit, which is commonly used in the bearing industry. The second step of research was the radial clearance measurement using measuring device that was described in sub-section 2.1. The presentation and analysis of the research results were the last step of research procedures.

\subsection{Research results}

The research results were presented in table and as diagrams showing the relationships between the level of vibrations and the values of radial clearance of examined bearings. Due to the large number of the measurement results, in the Table 1 were presented: mean values $(\bar{x})$, maximum values $\left(x_{\max }\right)$, minimum values $\left(x_{\min }\right)$ and mean deviations $(s)$ of measured values.

Tab. 1: Measurement results

\begin{tabular}{ccccc}
\hline \multirow{2}{*}{ Radial clerance $\Delta \mathbf{R}$} & \multicolumn{3}{c}{ Vibration level } \\
\cline { 2 - 5 } & $\mathrm{mm}$ & LB & MB & HB \\
\hline $\bar{x}$ & 0.019 & 6.91 & 8.37 & 2.33 \\
\hline$x_{\max }$ & 0.024 & 11.80 & 21.40 & 4.00 \\
\hline$x_{\min }$ & 0.012 & 4.10 & 3.42 & 1.67 \\
\hline$s$ & 0.0036 & 1.419 & 3.712 & 0.616 \\
\hline
\end{tabular}

In order to carry out the accurate analysis of the influence of the radial clearance values on the vibration level, the research results were grouped depending on the obtained radial clerance values $\Delta \mathrm{R}$ (from the smallest to the highest values). Then the measurement results were presented in the form of diagrams showed the influence of the increase of radial clearance values on the vibration level that was analyzed in different frequency bands. Moreover, in order to facilitate the analysis of the obtained results, the line trends were marked on the charts in Figure 3.

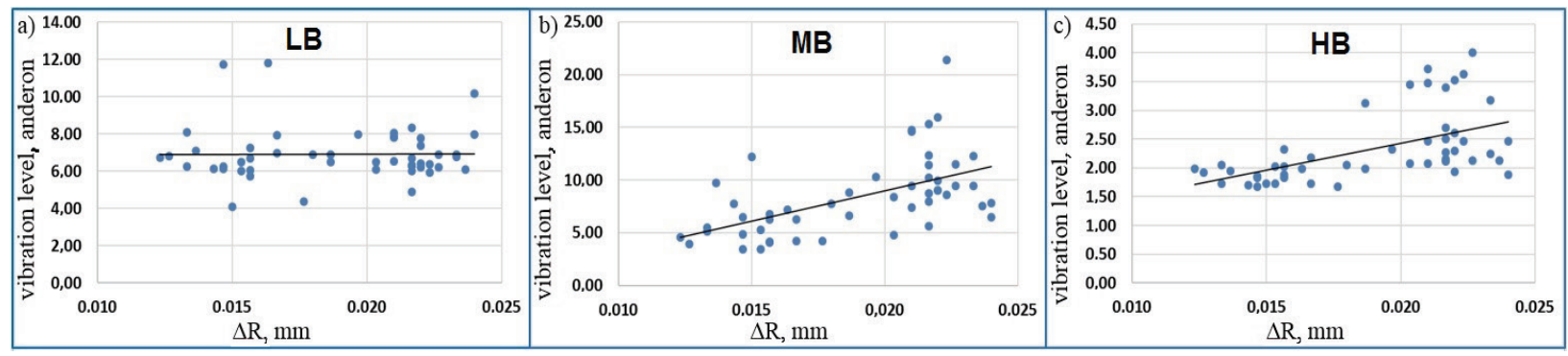

Fig. 3: Diagrams of the relationship between the values of the bearing radial clearance and bearing vibration level, where: a) $L B$ - low frequency bandwidth, b) $M B$ - medium frequency bandwidth, c) $H B$ - high frequency bandwidth. 
The experimental results indicated that the values of radial clearance of examined bearings were in range $\Delta \mathrm{R} \epsilon<0.012 \mathrm{~mm}, 0.024 \mathrm{~mm}>$ (see Table 1). These values slightly exceed the values of normal clearance. However, based on the results of vibration analysis, it can be concluded that the dominant vibration values were obtained in medium frequency band from 300 to $1800 \mathrm{~Hz}$. This may indicate excessive values of raceways waviness deviation (Adamczak, 2017a). Analyzing the results presented in Figure 3 it can be concluded that the increase the values of radial clearance causes an increase in the values of vibration level analysed in medium and high frequency band (see Fig. 3a and Fig. 3b). However, this increase is higher for the medium frequency band. Whereas, the vibration examined in low frequency band from 50 to $300 \mathrm{HZ}$ remain at a constant level despite the increase of the radial clearance values.

\section{Conclusions}

The main purpose of the research presented in this paper was to assess the influence of the bearing radial clearance on the basic exploitation parameter of rolling bearing such as vibration level. In many case, rolling bearings manufacturers do not present detailed information about radial clearance values, but only classify bearing into specific group of clearance. Excessive values of internal clearance affect the exploitation parameters of rolling bearing and thus on the condition of entire mechanisms. Based on research results it can be concluded that the examined bearing according to the standard ISO 5753 are classified into "C3" group of the clearance. These are bearings with enlarged clearance. This type of the bearing can work with higher rotational speed but generates higher value of vibration, which has been confirmed by experimental research presented in this paper. Vibration analysis indicated that the dominant vibration values has been noted in the medium frequency band. Moreover, the increase the radial clearance value results in increased vibration level in medium and high frequency band. Generally, it is assumed that the vibration generated in frequency range from 300 to $1800 \mathrm{~Hz}$ largely results from surface irregularities of bearing raceways and balls. However, as shown by research results presented in this paper, value of the bearing radial clearance also affects the vibration level recorded in medium and high vibration frequency band. This information should be taken into account when analyzing the bearing vibration measurement results. The research presented in this paper are of initial research. In future work, the author will study other factors affecting the value of vibration level generated by ball rolling bearings i.e. geometry of raceways and balls, lubrication type. Moreover, the dominant factors will be indicated.

\section{Acknowledgement}

The research presented in this paper was supported by the National Science Centre of Poland under the scientific work No. 2017/01/X/ST2/00155.

\section{References}

Adamczak, S. and Zmarzły, P. (2017a) Influence of raceway waviness on the level of vibration in rolling-element bearings. Bulletin of the Polish Academy of Sciences Technical Science, 64, 2, pp. 45-52.

Adamczak, S., Stępień, K. and Wrzochal, M. (2017b) Comparative study of measurement systems used to evaluate vibrations of rolling bearings. Procedia Engineering, 192, pp. 971-975.

Aschenbrenner, A. and Wartzack, S. (2016) A concept for the consideration of dimensional and geometrical deviations in the evaluation of the internal clearance of roller bearings. Procedia CIRP, 43, pp. 256-261.

Błasiak, S. (2016) Time-fractional heat transfer equations in modeling of the non-contacting face seals. International Journal of Heat and Mass Transfer, 100, pp. 79-88.

Cui, L., Zhang, Y., Zhang, F., Zhang, J., Lee, S. (2016) Vibration response mechanism of faulty outer race rolling element bearings for quantitative analysis. Journal of Sound and Vibration, 364, pp. 67-76.

Kaczor, J. (2014) Effect of clearance the ball bearings on incorrect work of three-support bearing shaft. Zeszyty Naukowe Politechniki Śląskiej, 83, 117-126.

Petersena, D., Howarda, C., Sawalhi, N., Ahmadi, A.M., Singh, S. (2015) Analysis of bearing stiffness variations, contact forces and vibrations in radially loaded double row rolling element bearings with raceway defects. Mechanical Systems and Signal Processing, 50-51, pp. 139-150.

Kıral, Z. and Karagülle, H. (2006) Vibration analysis of rolling element bearings with various defects under the action of an unbalanced force. Mechanical Systems and Signal Processing, 20, pp. 1967-1991.

Smolík, L., Hajžman, M. and Byrtus, M. (2017) Investigation of bearing clearance effects in dynamics of turbochargers. International Journal of Mechanical Sciences, 127, pp. 62-72. 